\title{
Programme for International Student Assessment (PISA)
}

\author{
ACER leads an international consortium of research \\ organisations, and educational institutions to \\ deliver the International PISA project on behalf of \\ the Organisation for Economic Cooperation and \\ Development (OECD).
}

Translated into 48 languages and then verified to ensure they can be understood by students from a wide range of language and cultural backgrounds, PISA questions are based on relevant, everyday situations. PISA tests the reading, mathematics and science literacy of 15-year-olds across the world. In 2009 around 400000 students from 57 countries took part.

The OECD established PISA, which is a means of assessing and comparing education systems worldwide, after discovering it had a number of economic measures of its member countries but no measures of educational achievement. By testing the skills and knowledge of 15-yearolds in three core subject areas, PISA determines how capable students are at applying their skills and knowledge to real-life problems and situations, and whether they can analyse, reason and communicate their ideas effectively.

By assessing students at the age when they are nearing the end of compulsory schooling, PISA ascertains whether students are prepared for the challenges of life as young adults.

Since 2000, PISA has been conducted every three years. The continuous cycle of PISA allows for longitudinal trends in educational performance to be monitored.

The PISA test includes questions on a particular subject area accompanied by stimulus material, which may include text, diagrams or images, and is followed by a questionnaire that asks students about their attitudes and background. This questionnaire seeks to gain information about students' home and school environment to identify possible influences on school achievement. The questions used in PISA are carefully developed and selected. Expert groups are consulted, ideas are discussed among participating countries and advice is sought from various boards and groups. Every item included is rated by each country in terms of potential cultural, gender or other biases, as well as the relevance to 15-year-olds' familiarity and level of interest. The questions are tested in field trials in participating countries before they are considered to be part of the main PISA study.

When PISA is conducted every three years a nationally representative sample of 15-year-olds is chosen from each participating country. The sample is carefully designed to ensure that PISA provides an accurate snapshot of educational achievement of the full 15-year-old population. 
Once the tests are completed a team of specially trained markers checks them. The data is then sent back to the PISA consortium and collated with that of other countries to create an international database. The database created provides a multitude of information that may eventually be used to inform educational policy in participating countries. Information from the attitude and background questionnaire is used to analyse potential influences on students' performance across and within countries.

The data collected by PISA shows the successes of schools in some countries, and the challenges faced by others. It allows countries to compare best practices and to further develop an educational reform agenda appropriate for their particular school system.

\section{Example question from PISA}

\section{BRAKING}

The approximate distance to stop a moving vehicle is the sum of:

- the distance covered during the time the driver takes to begin to apply the brakes (reaction-time distance)

- the distance travelled while the brakes are applied (braking distance)

The 'snail' diagram below gives the theoretical stopping distance for a vehicle in good braking conditions (a particularly alert driver, brakes and tyres in perfect condition, a dry road with a good surface) and how much the stopping distance depends on speed.

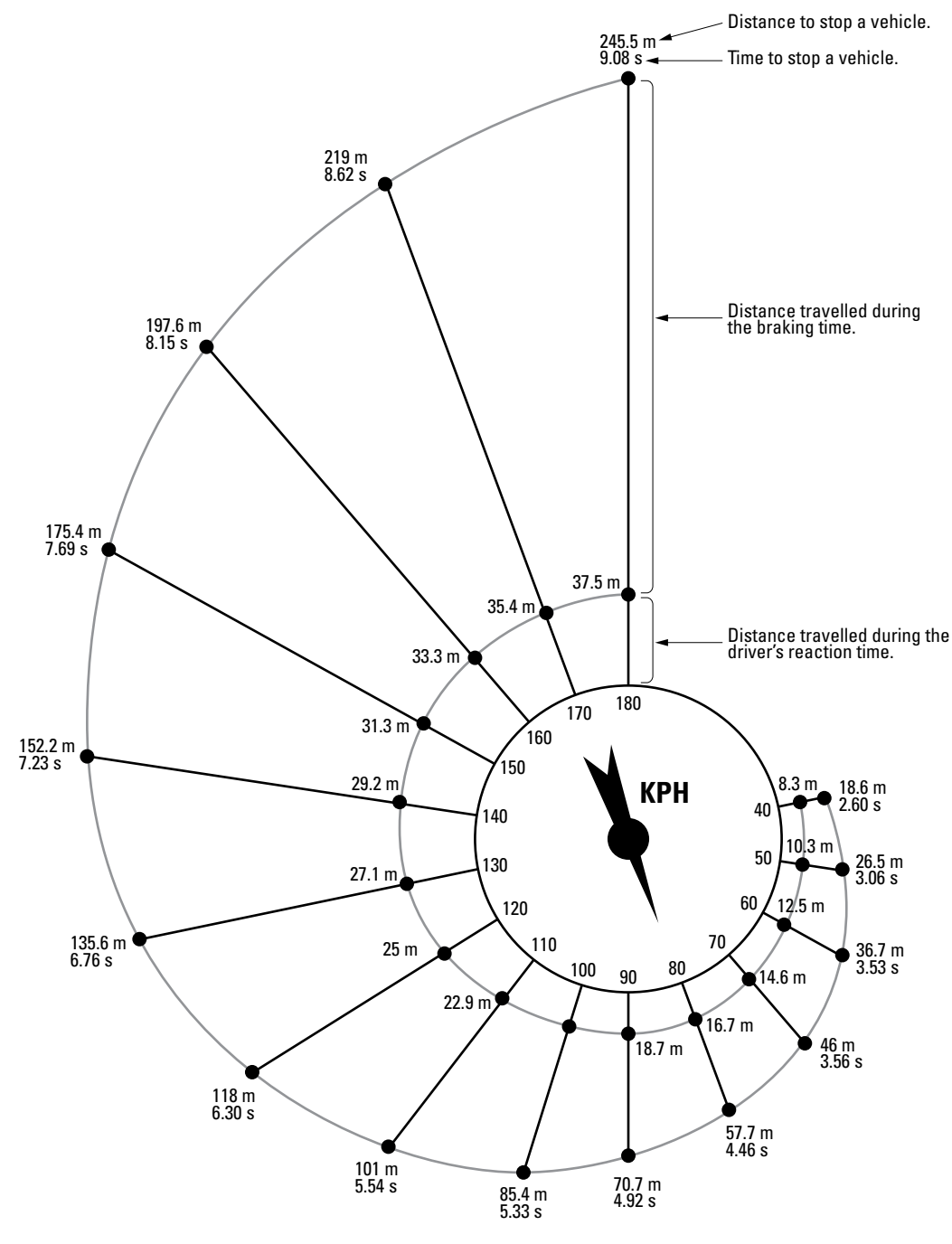

Source: La Prévention Routière, Ministère de l'Education nationale de la Recherche et de la Technologie, France.

If a vehicle is travelling at $110 \mathrm{kph}$, what distance does the vehicle travel during the driver's reaction time? 


\section{PISA Case studies}

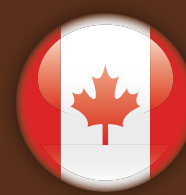

\section{Canada}

- Canada's PISA results reflect the country's strong education system.

- PISA has contributed to the strengthening of assessment systems in core subject areas.

- Relatively lower PISA results in some provinces have led to the introduction of new research and assessment initiatives.

Canada was drawn to take part in PISA because it is not just a global benchmark that ranks the success of education systems around the world, but looks at the preparedness of students as they embark on post-secondary studies or enter the workforce. While provincial, territorial and national systems of assessment in Canada are most closely related to school curricula, PISA focuses on life skills, which are fundamental in a global economy.

Canada's PISA results have been relatively good so most jurisdictions have not felt the need for significant education reforms based on PISA. However, in some jurisdictions PISA has contributed to the strengthening of assessment systems, mostly in core subject areas. Provinces that showed relatively lower results in PISA 2000 and PISA 2003 have introduced new research and assessment initiatives.

Information courtesy of PISA National Project Manager for Canada.

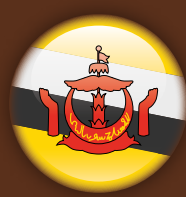

\section{Dubai}

- Newcomer to the PISA program.

- Taking part in PISA to compare its national educational performance internationally.

For Dubai, PISA generates consistent, high quality indicators of student knowledge in reading, mathematics and science at a point where compulsory schooling is at or nearing an end. PISA also helps identify weaknesses and strengths in the country's schooling system in some key areas such as education standards, national student performance, curriculum structure and content, and school administration. It also allows Dubai to compare its education system internationally.

Dubai is a relative newcomer to PISA, having taken part for the first time in 2009. The emirate is still working through the results of that first cycle.

Information courtesy of PISA National Project Manager for United Arab Emirates.

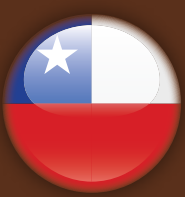

\section{Chile}

- Taking part in PISA allows Chile the opportunity to be on par with developed nations.

- PISA has indirectly influenced the development of the schoo curriculum in Chile.

Chile has a long tradition of assessment. National testing has been conducted in the South American country for more than a decade, providing schools and administrators with valuable feedback concerning what needs to be done to improve student learning. However, national tests are not enough to give a full understanding of a country's education system. International studies such as PISA allow Chile to be part of a global movement that looks at how students perform with the knowledge they acquire about the present and future world. Assessments such as PISA are invaluable for nations like Chile, which seek to provide better possibilities for their citizens.

Participating in PISA has allowed Chile to put its education system under international scrutiny as well as enable data to be collected about student performance to inform policy makers and educators. PISA has indirectly influenced curriculum experts in Chile to develop progress maps and, in turn, new curriculum adjustments through its framework.

Information courtesy of PISA National Project Manager for Chile.
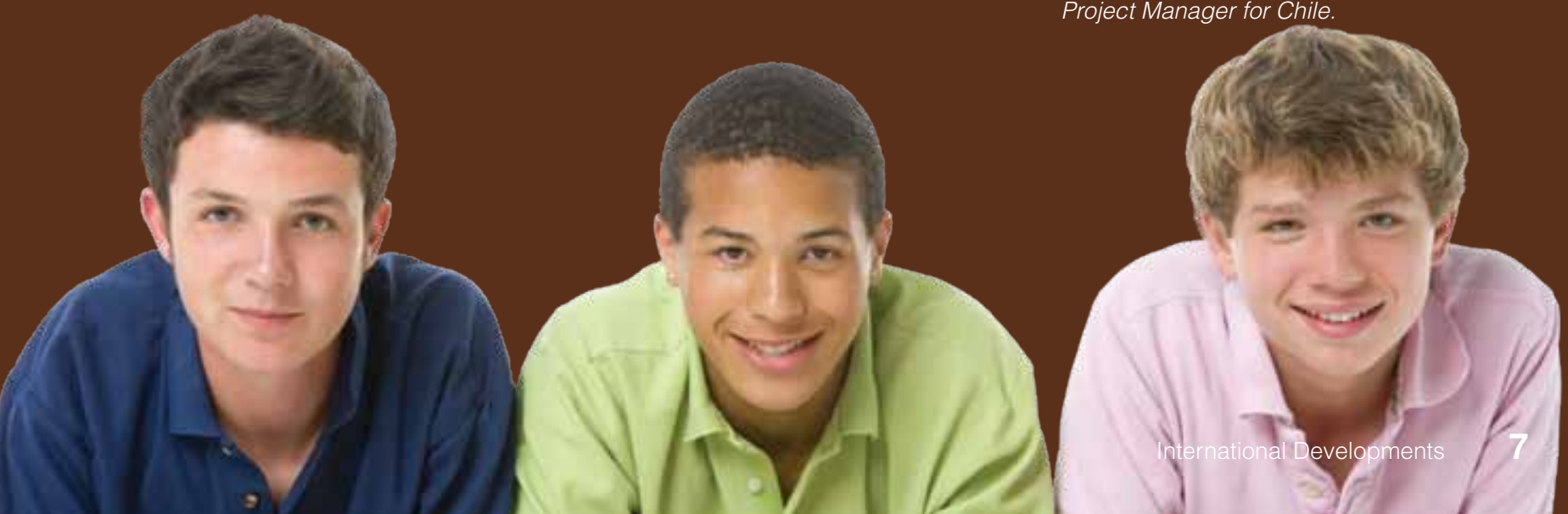